\title{
Effects of Ru content on phase transformation and compression property of cast TiAl alloys
}

\author{
*Jie-ren Yang ${ }^{1,2}$, Zi-xiang Jiao', Dong-dong Zhu', Yu-lun Wu', Zi-tong Gao', Rui Hu, ${ }^{1,2}$ \\ 1. State Key Laboratory of Solidification Processing, Northwestern Polytechnical University, Xi'an 710072, China \\ 2. Shaanxi Key Laboratory of High-Performance Precision Forming Technology and Equipment, Northwestern Polytechnical University, Xi'an \\ 710072, China \\ 3. School of Mechanical Engineering \& Key Laboratory of Air-driven Equipment Technology of Zhejiang Province, Quzhou University, Quzhou \\ 324000, China
}

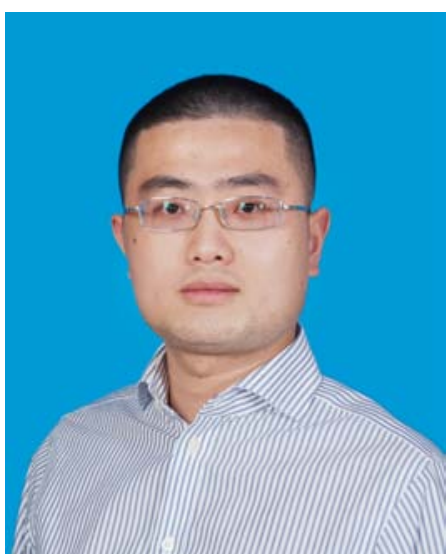

*Jie-ren Yang

Ph.D., Associate Professor. He is engaged in the research on theoretical design, solidification and processing, microstructure modification, and phase transformation behavior of TiAl alloys, precious metal and superalloys.

E-mail: yangjieren@nwpu.edu.cn

Received: 2020-06-16

Accepted: 2020-08-23
Abstract: Ruthenium (Ru) is a promising element to heighten the comprehensive mechanical properties of TiAl alloys. In the present study, the phase transformation during the cooling of Ti-47Al-2Cr-2Nb-xRu $(x=0,0.1,0.5,1.0$, at.\%) alloys was investigated. The results show that $\mathrm{Ru}$ tends to segregate in the interdendritic region during solidification, and therefore, refines the as-cast microstructure of the alloys. As a $\beta$-stabilizer, Ru does not induce a novel solidification reaction but maintains the peritectic reaction of $L+\beta \rightarrow \alpha$. An excessive $R u$ content would cause the formation of $\left(\gamma+\tau_{1}+B 2\right)$ and $\left(\alpha+\gamma+\tau_{1}+B 2\right)$ phase regions below $1,250{ }^{\circ} \mathrm{C}$. The precipitation of $\tau_{1}$-containing mixture is attributed to the Ru-segregation, which inhibits the reaction of $\alpha \rightarrow \gamma$ and facilitates the formation of B2 phase. The discontinuous coarsening of $y$ phase and block $\tau_{1}$ phase formed alternately in a manner of analogous eutectoid decomposition within B2 phase. In addition, the effect of Ru content on compression property of the alloys was studied. The yield strength increases up to $427 \mathrm{MPa}$ at $800{ }^{\circ} \mathrm{C}$ with the addition of 1.0 at. \% $\mathrm{Ru}$, which is mainly due to the solution strengthening effect of $\mathrm{Ru}$.

Key words: TiAl alloy; solidification path; microstructure; phase transformation; yield strength

CLC numbers: TG146.23; Document code: A; Article ID: 1672-6421(2020)06-393-09

$\mathrm{T}$ Al alloys have attracted extensive attention for aerospace applications due to their advantages of low density, high specific strength and good oxidation resistance ${ }^{[1-3]}$. However, the low room-temperature (RT) ductility and relatively low creep resistance constrain the development of TiAl alloys ${ }^{[4,5]}$. Alloying is an effective method to heighten the properties of TiAl alloys ${ }^{[6]}$. Particularly, the addition of $\beta$-stabilizing elements, such as $\mathrm{Nb}$ and $\mathrm{Mo}$, can impede the elemental diffusion and hence improve the mechanical properties at elevated temperatures ${ }^{[3,7]}$.

Precious metal element $\mathrm{Ru}$, as a highly effective $\beta$-stabilizer ${ }^{[8]}$, has been considered as a potential element doping into TiAl alloys ${ }^{[9-11]}$. Kim et al. ${ }^{[9]}$ proved that Ru could decrease the value of $\mathrm{c} / \mathrm{a}$ and the unit cell volume, which might improve the room temperature ductility. Khataee et al. ${ }^{[8]}$ proposed eight solidification reactions in the TiAl-Ru ternary phase diagram. Further, Grytsiv et al. ${ }^{[10]}$ modified the phase equilibria of Ti-Al-Ru based on the results of Khataee et al. ${ }^{[8]}$ and presented two other solidification reactions. Recently, Liu et al. ${ }^{[1]}$ revealed that the slight addition of Ru could obviously influence the microstructures and mechanical properties of TiAl alloys at high temperature. However, the low solubility of Ru element in TiAl alloys prompts the formation of a ternary phase $\tau_{1}$, which arouses an extensive controversy on the solidification path. The previous studies were mainly restricted to some high-Ru content ternary alloys, but rarely focused on multi-element TiAl alloys with trace Ru addition. 
In this study, the effects of Ru content on the solidification path and phase transformation in Ti-47Al-2Cr-2Nb- $x \mathrm{Ru}$ alloys were investigated. The microstructure evolution and phase transformation mechanism were discussed. Moreover, the compression tests were conducted at $800{ }^{\circ} \mathrm{C}$, and the strengthening mechanism of Ru was analyzed.

\section{Experimental method}

Button ingots with the nominal compositions of Ti-47Al-2Cr$2 \mathrm{Nb}-x \mathrm{Ru}(x=0,0.1,0.5,1.0)$ (at.\%, the same hereafter), weighing approximately $80 \mathrm{~g}$, were prepared by vacuum arc melting using high-purity titanium sponges, aluminium ingots, chromium and niobium blocks as well as ruthenium powders. The alloys were remelted four times to ensure chemical homogenization and then solidified in a water-cooled copper crucible. The samples for heat treatment with the size of $6 \mathrm{~mm} \times 6 \mathrm{~mm} \times 6 \mathrm{~mm}$ were cut and then subjected to different heat treatment processes. The heat treatment parameters were confirmed according to the TiAl binary phase diagram, as shown in Fig. 1. After isothermal holding (IH) at $1,450{ }^{\circ} \mathrm{C}$ (in the $\alpha$ single-phase region ${ }^{[12]}$ ) for $15 \mathrm{~min}$, samples used for microstructure analysis were cooled to $800{ }^{\circ} \mathrm{C}$ at the cooling rate of $5 \mathrm{~K} \cdot \mathrm{min}^{-1}$ followed by water quenching. The other samples were cooled to different temperatures $\left(1,350{ }^{\circ} \mathrm{C} ; 1,300{ }^{\circ} \mathrm{C} ; 1,250{ }^{\circ} \mathrm{C}\right.$ and $\left.1,200{ }^{\circ} \mathrm{C}\right)$ and held for $1 \mathrm{~h}$, followed by water quenching. The as-cast ingots for compression testing were treated by hot isostatic pressuring (HIP) at $1,280{ }^{\circ} \mathrm{C}$ for $4 \mathrm{~h}$ under $140 \mathrm{MPa}$. The compression samples with $\Phi 6 \mathrm{~mm} \times 9 \mathrm{~mm}$ in size were cut from the HIP ingots. The compression tests at $800{ }^{\circ} \mathrm{C}$ were carried out on a Gleeble-3500 thermal simulator at a strain rate of $1 \times 10^{-3} \mathrm{~s}^{-1}$.

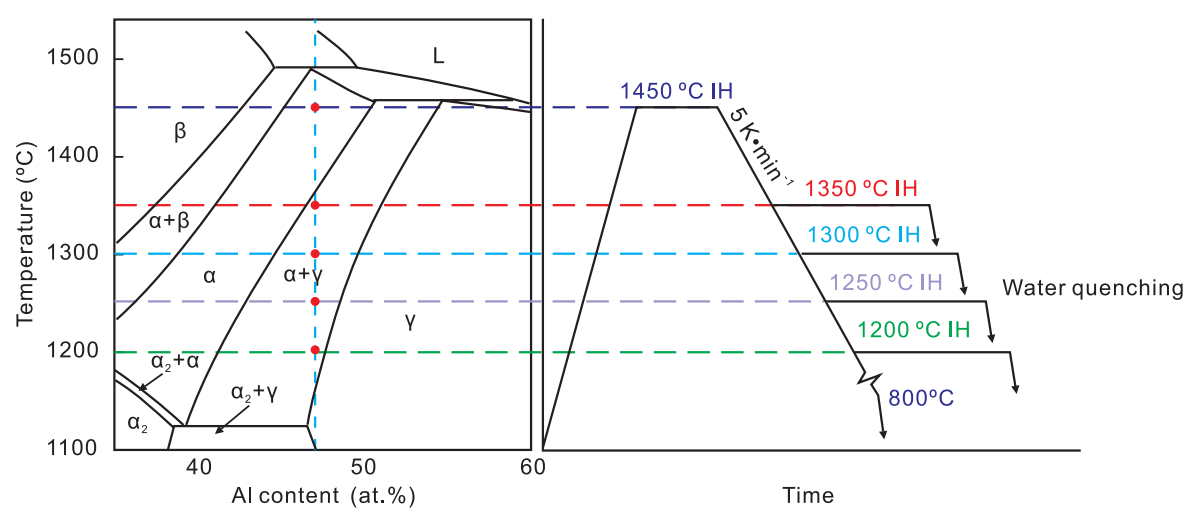

Fig. 1: Heat treatment parameters based on the Ti-Al binary phase diagram ${ }^{[12]}$

The as-cast, heat treated, and HIP samples were polished by a standard metallographic approach. The microstructures were observed using the scanning electron microscopy (SEM, FEI Verios G4 type) with a back-scattered electron (BSE) mode and transmission electron microscopy (TEM, FEI Talos F200x type) under bright field (BF). The energy dispersive spectrometer (EDS) and scanning transmission electron microscopy (STEM) using a high-angle annular dark-field (HAADF) detector were employed to detect the chemical distribution. The phase composition was determined by X-ray diffraction (XRD, SHIMADZU X'Pert PRO) and selected area electron diffraction (SAED). In addition, the semi-quantitative method by applying ImagePro Plus (IPP) software was used to count the average lamellar colony size and the phase volume fraction based on at least 10 micrographs ${ }^{[13]}$.

\section{Results and discussion}

\subsection{Microstructures of Ru-containing TiAl alloys}

\subsubsection{As-cast microstructure}

The SEM-BSE images of the as-cast samples are shown in Fig. 2. No obvious segregation is observed in Ti-47Al$2 \mathrm{Cr}-2 \mathrm{Nb}$ alloy in Fig. 2(a). The worm-like $\beta$-segregation in the dendrite central region and dark grey interdendritic solidification segregation (S-segregation) caused by peritectic solidification ${ }^{[14]}$ are observed with $0.1 \% \mathrm{Ru}$ addition, as shown in Fig. 2(b). However, it is unusual that some bright precipitations distributed in the interdendritic regions mixing with S-segregation ${ }^{[15]}$, which might be the B2 phase, as also found in a 4822-GE alloy ${ }^{[16]}$. With the increase of Ru content [Fig. 2(c)], the characteristics of the peritectic solidification are still maintained in the as-cast microstructure, with the wormlike $\beta$-segregation distributing in dendrites. However, the $\mathrm{S}$-segregation is replaced by a $\tau_{1}$-containing mixture with a size of 50-60 $\mu \mathrm{m}$, which is possibly composed of B2 $+\gamma+\tau_{1}$ phases ${ }^{[11]}$. When the content of $\mathrm{Ru}$ reaches $1.0 \%$, the segregation region obviously enlarges and distributes as a discontinuous network [Fig. 2(d)], which is similar to the previous study ${ }^{[17]}$.

The chemical composition of the interdendritic $\gamma$ phase and B2 phase in as-cast Ti-47Al-2Cr-2Nb-0.1Ru (4722-0.1Ru) alloy detected by EDS are listed in Table 1. The results corresponded to the solidification partitions of $\mathrm{Nb}$ and $\mathrm{Cr}$ elements, as $\mathrm{Nb}$ element enriched within the dentrite ${ }^{[18]}$ and $\mathrm{Cr}$ is rejected to the interdendritic region. The formation of $\mathrm{B} 2$ phase in the interdendritic region accounts for the $\mathrm{Cr}$-segregation during solidification ${ }^{[16,19]}$. Besides, as $\mathrm{Ru}$ is the $\beta$-phase stabilizing element, it is obvious that Ru preferentially enriches in liquid 

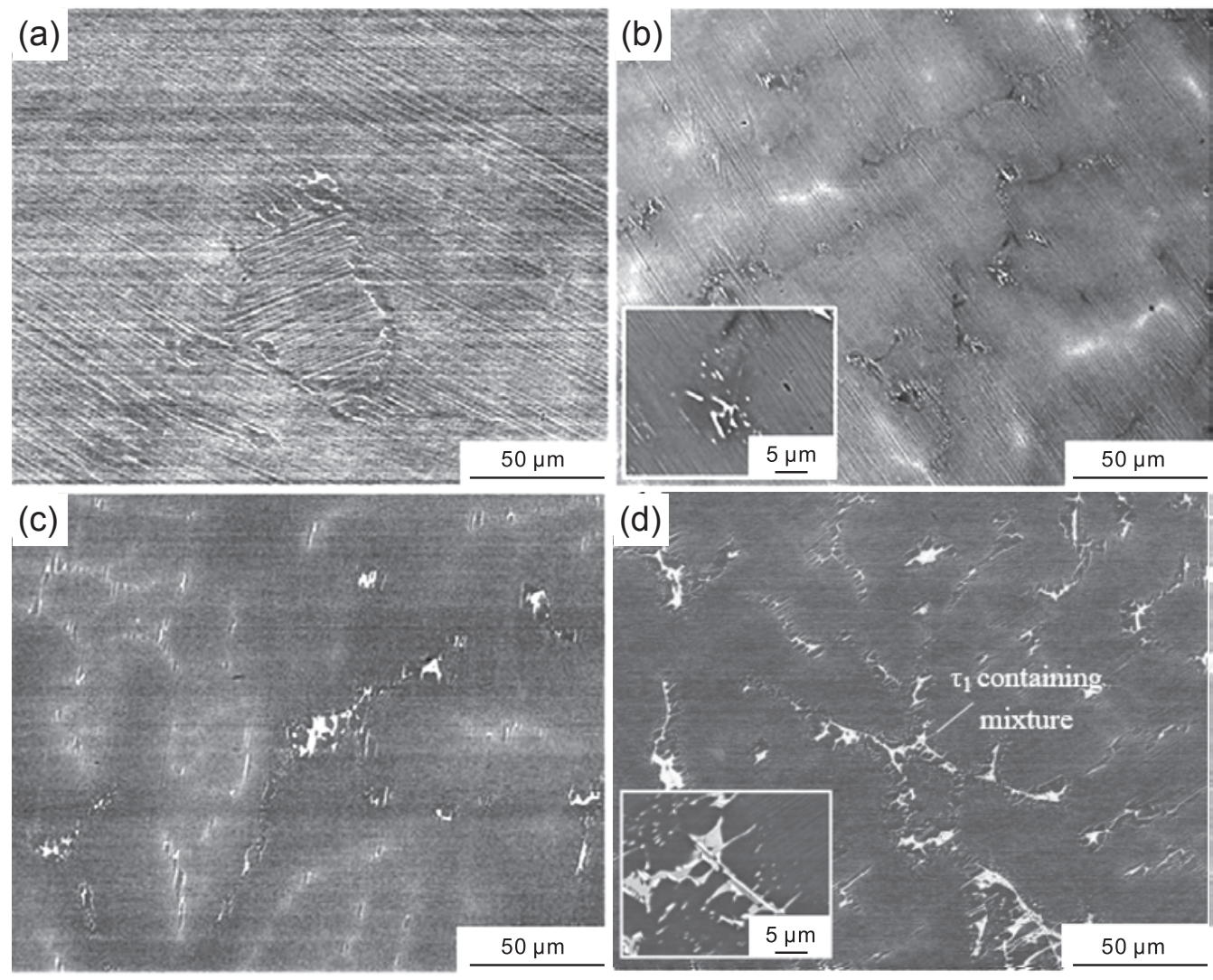

Fig. 2: BSE images of as-cast Ti-47Al-2Cr-2Nb-xRu alloys: (a) $x=0$; (b) $x=0.1$; (c) $x=0.5$ and (d) $x=1.0$

Table 1: Chemical composition of interdendritic $\gamma$ phase and B2 phase in as-cast Ti-47Al-2Cr-2Nb-0.1Ru alloy

\begin{tabular}{cccccc} 
& \multicolumn{5}{c}{ Elemental composition (at.\%) } \\
Interdendritic phase & $\mathrm{Ti}$ & $\mathbf{A l}$ & $\mathbf{C r}$ & $\mathrm{Nb}$ & $\mathbf{R u}$ \\
\hline Y phase & 47.34 & 48.27 & 2.46 & 1.65 & 0.27 \\
B2 phase & 46.00 & 37.70 & 13.14 & 1.18 & 1.98
\end{tabular}

phase ${ }^{[16]}$. Hence, it can be concluded that the $\tau_{1}$-containing mixture in the cast $\mathrm{Ti}-47 \mathrm{Al}-2 \mathrm{Cr}-2 \mathrm{Nb}-(0.5,1.0) \mathrm{Ru}$ alloys is located in the interdendritic Ru-rich regions. The average lamellar colony size of as-cast Ti-47Al-2Cr- $2 \mathrm{Nb}-x \mathrm{Ru}(x=0,0.1$, $0.5,1.0$ ) alloys is shown in Table 2 . The lamellar colony size is significantly refined by the segmentation of the second phase, which is most likely related to severe Ru-segregation resulting from the peritectic solidification path.

Table 2: Average lamellar colony size of as-cast Ti-47Al-2Cr-2Nb-xRu $(x=0,0.1,0.5,1.0)$ alloys

\begin{tabular}{|ccccc|}
\hline Ru content & $x=0$ & $x=0.1$ & $x=0.5$ & $x=1.0$ \\
\hline Average lamellar colony size $(\mu \mathrm{m})$ & 250 & 236 & 160 & 110
\end{tabular}

\subsubsection{Microstructures after homogenizing in single $\alpha$ phase field}

In order to eliminate the S-segregation in cast TiAl-Ru alloys, a homogeneous heat treatment was performed. It is observed that all samples exhibit the fully lamellar structure with the grain size above $800 \mu \mathrm{m}$ in Fig. 3(a) and (b). The lack of pinning effect of the $\gamma$ phase at $1,450{ }^{\circ} \mathrm{C}^{[12]}$ leading to the fast coarsening of $\alpha$ grains. However, when the $\mathrm{Ru}$ content reaches $1.0 \%$, the SEM-BSE image shows that some $\tau_{1}$-containing mixtures randomly distribute in the center of lamellar colony, as well as its boundary in Fig. 3(c). With the similar $\tau_{1}$ particles alternately distributing in the mixture of block B2 phase and massive $\gamma$ phase, the size of constituent phase after homogenization is larger than the one that formed during solidification, as shown in Fig. 3(d).

To clarify the formation of the $\tau_{1}$-containing mixture in the heat-treated alloy with $1.0 \mathrm{at} . \% \mathrm{Ru}$, a TEM characterization was conducted. The bright field (BF) images of the alloy are shown in Fig. 4(a) and (b). Figure 4(d)-(g) shows the morphology of $\tau_{1^{-}}$ containing mixture and elemental distributions of $\mathrm{Ti}, \mathrm{Al}$ and $\mathrm{Ru}$ acquired by STEM-HAADF. The SAED patterns of Region 1 reveals that the selected area corresponds to $\tau_{1}$ phase in Fig. 4(c). According to the elemental distribution in Fig. 4(e)-(g), the similar Ru enrichment is observed in Areas 3 and 4 in Fig. 4(d), whereas Ti element is abundant in Areas 1 and 2. Therefore, Areas 3 and 4 are $\tau_{1}$ phase, while Areas 1 and 2 represent the 

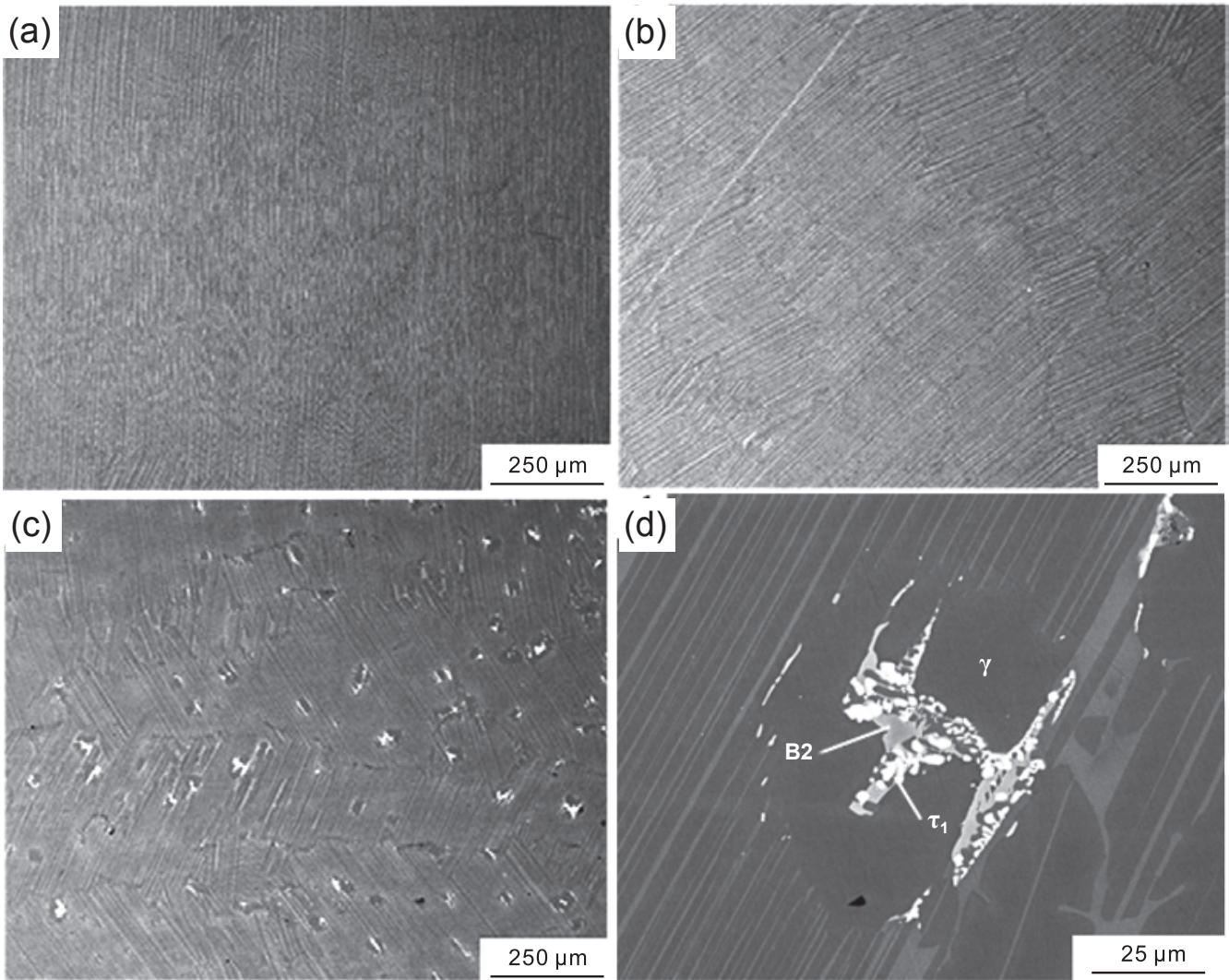

Fig. 3: BSE images of Ti-47Al-2Cr-2Nb-xRu alloys after homogenization treatment: (a) $x=0.1$; (b) $x=0.5$; (c) $x=1.0$; (d) high-magnification image of $\tau_{1}$-containing mixture
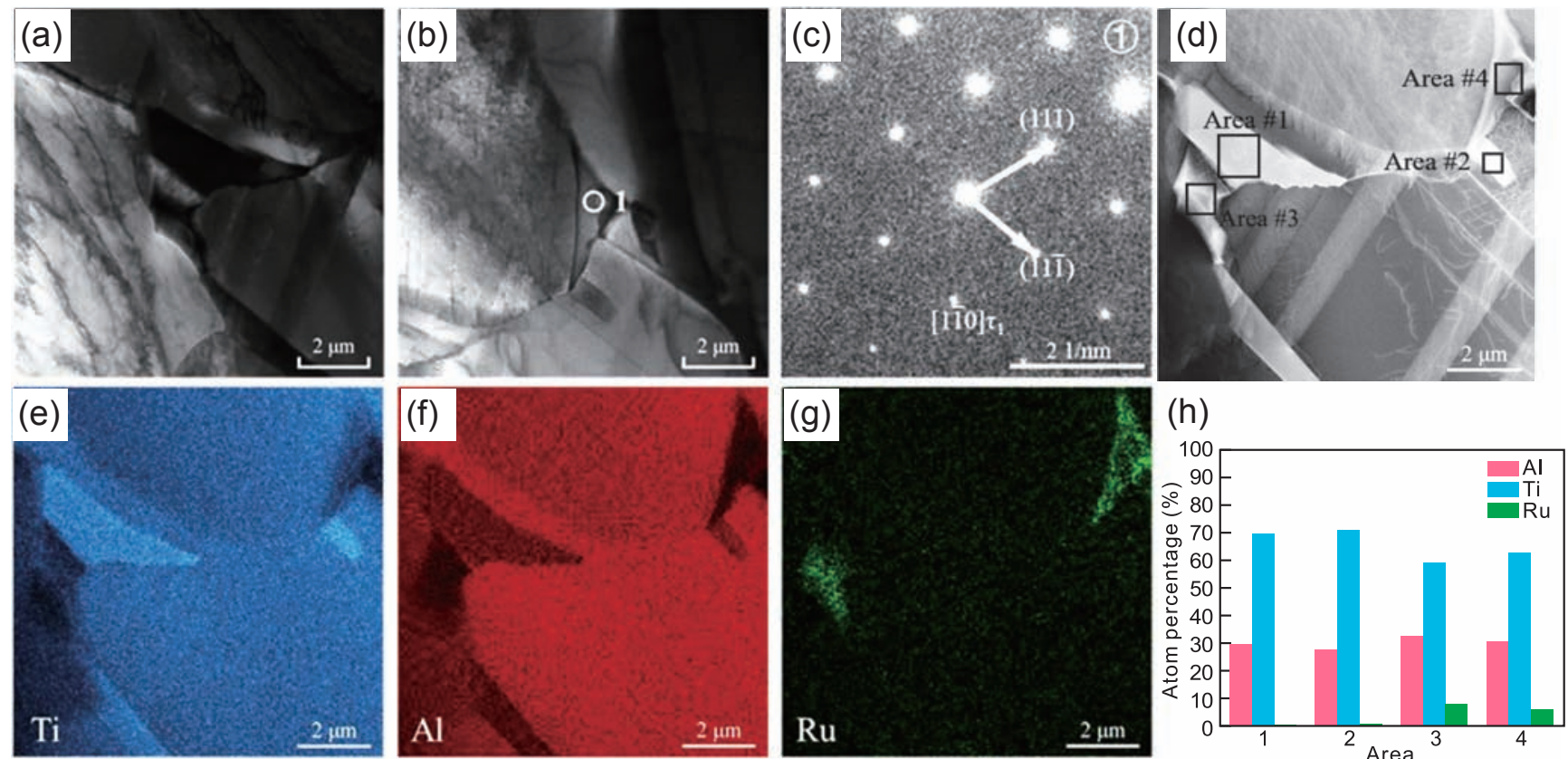

Fig. 4: (a)-(c) BF images and SAED patterns of homogenized Ti-47Al-2Cr-2Nb-1.0Ru alloy; (d)-(g) STEM-HAADF morphology and element distributions of $\mathrm{Ti}, \mathrm{Al}$ and $\mathrm{Ru}$; (h) elemental fraction in Areas 1-4

$\mathrm{B} 2$ phase. Note that the percentage of $\mathrm{Ru}$ atom in $\tau_{1}$ phase is higher than that in $\mathrm{B} 2$ phase, and the percentage of $\mathrm{Ru}$ in $\mathrm{B} 2$ phase is below 1.0at.\%, as shown in Fig. 4(h). The content transition of $\mathrm{Ru}$ element was observed between $\mathrm{B} 2$ phase and adjacent $\tau_{1}$ phase particles in Fig. $4(\mathrm{~g})$. Thus, the precipitation of $\tau_{1}$ phase is most likely involved with the solute diffusion and the elemental enrichment of $\mathrm{Ru}$ in the $\mathrm{B} 2$ phase.

\subsubsection{Microstructure after quenching at different temperatures}

To understand the effect of Ru content on the phase transformation and solidification path in Ti-47Al-2Cr-2Nb$x \mathrm{Ru}$ alloys, samples were firstly heated to $1,450{ }^{\circ} \mathrm{C}$ and cooled to different temperatures followed by water quenching. The SEM-BSE images of the quenched Ti-47Al-2Cr-2Nb- $x$ Ru 
alloys are shown in Fig. 5. After water quenching at $1,350{ }^{\circ} \mathrm{C}$, the net-like structure randomly forms in the alloys with 0.5 at. $\%$ and $1.0 \mathrm{at} . \% \mathrm{Ru}$. Wu et al. ${ }^{[20]}$ proposed that the netlike structure is formed via a eutectoid reaction $\alpha \rightarrow \tau_{1}+\gamma$.

Several eutectoid-forming elements, such as $\mathrm{Cu}, \mathrm{Ni}$ and $\mathrm{Si}$, are found to form active eutectoid system with $\mathrm{Ti}$ due to their fast transformation kinetics ${ }^{[21]}$, which means that it is difficult to inhibit eutectoid transformation in these systems even by quenching from high temperature. The morphology of $\tau_{1} / \gamma$ lamellar is corresponds exactly to the features of active eutectoid transformation with fine lamellar spacing. Due to the diffusion of $\mathrm{Ru}$ element being limited ${ }^{[22]}, \mathrm{Ru}$ is concentrated in some local regions even after the isothermal holding at $1,450{ }^{\circ} \mathrm{C}$. The local supersaturation of $\mathrm{Ru}$ promotes the active eutectoid reaction during water quenching. When the quenching temperature is $1,300{ }^{\circ} \mathrm{C}$, the lath-like $\gamma$ phase forms. However, the $\alpha / \gamma$ lamellar structure is interrupted by block $\alpha$ phase, as shown in Figs. 5(e) and (f), and the fraction of block $\alpha$ phase increases as $\mathrm{Ru}$ content increases.

Almost no changes are observed in microstructure of the alloy with $0.1 \mathrm{Ru}$ in the cases of $1,250{ }^{\circ} \mathrm{C}$ and $1,200{ }^{\circ} \mathrm{C}$, while the block $\alpha$ phase transformed into B2 phase in the alloys with

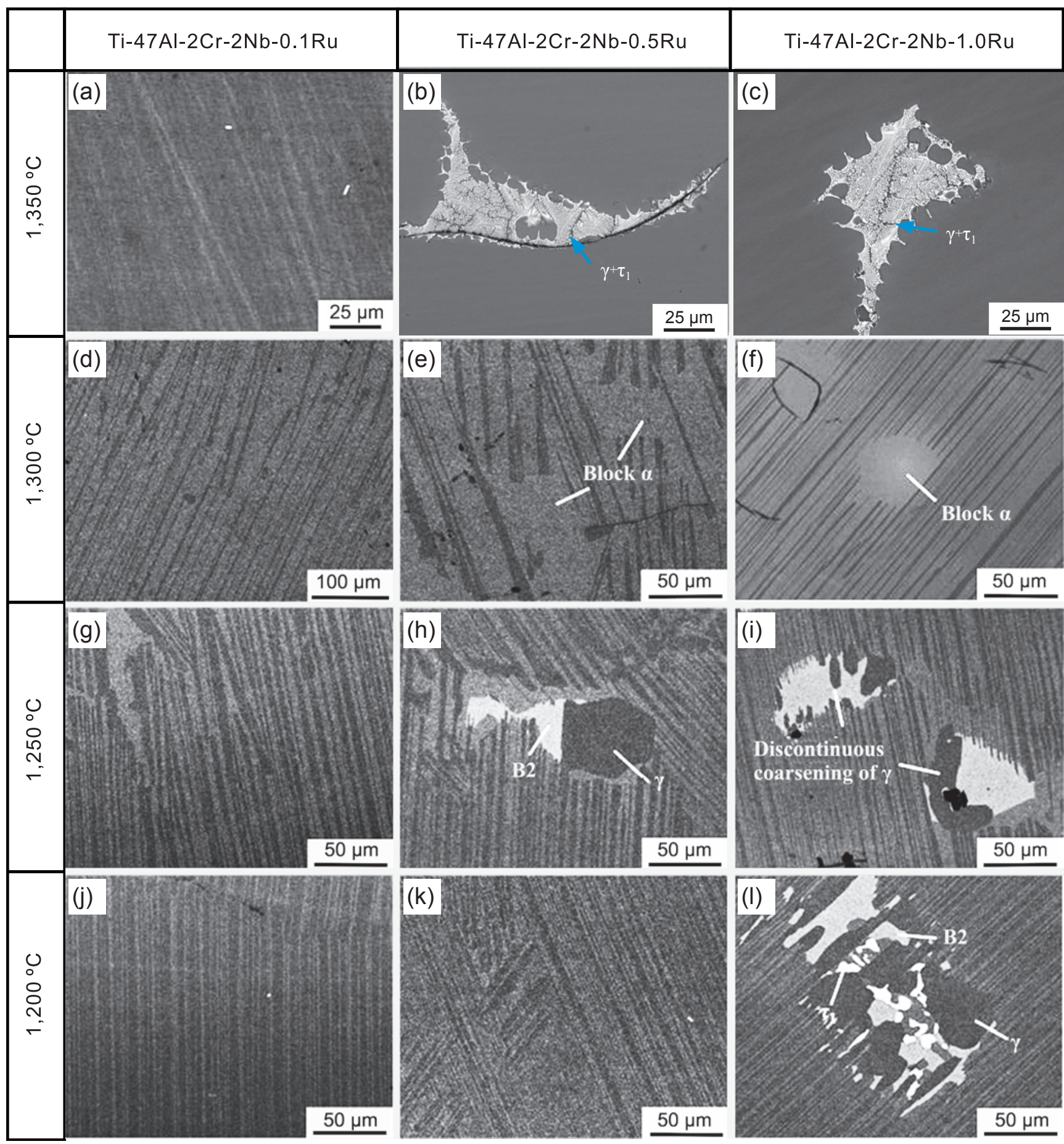

Fig. 5: BSE images of Ti-47Al-2Cr-2Nb-xRu $(x=0.1,0.5,1.0)$ samples quenched from: (a)-(c) $1,350{ }^{\circ} \mathrm{C}$; (d) $-(\mathrm{f}) 1,300{ }^{\circ} \mathrm{C}$; (g)-(i) $1,250{ }^{\circ} \mathrm{C}$ and (j)-(I) $1,200{ }^{\circ} \mathrm{C}$ 
0.5 at. $\%$ and $1.0 \mathrm{at} . \% \mathrm{Ru}$, which is similar to the $\alpha$-segregation in the high-Nb TiAl alloy ${ }^{[15]}$. It could be concluded that the block light grey regions are enriched in $\mathrm{Ru}$, which inhibits the reaction of $\alpha \rightarrow \gamma$ and facilitates the precipitation of B2 phase.

Figure 5(h) and (i) demonstrate that the discontinuous coarsening of $\gamma$ phase initiated at the interface of B2 phase and $\gamma$ laths at $1,250{ }^{\circ} \mathrm{C}$ in the alloys with 0.5 at. $\%$ and 1.0 at. $\%$ $\mathrm{Ru}$, obeying the Burgers orientation relationship ${ }^{[23,24]}$. As the quenching temperature decreases to $1,200{ }^{\circ} \mathrm{C}$, both $\mathrm{B} 2$ phase and coarsened $\gamma$ phase are transformed into lamellar structure in the alloy with 0.5 at. $\% \mathrm{Ru}$. Meanwhile, $\tau_{1}$ phase precipitates in the residual B2 phase with an alternative distribution due to the coarsening of $\gamma$ phase in the alloy with 1.0at.\% Ru.

\subsection{Solidification path of Ru-containing TiAl alloys}

Based on the as-cast and heat-treated microstructures above, referring to the Ti-Al binary phase diagram and the isothermal sections of Ti-Al-Ru ternary phase diagram ${ }^{[10]}$, the effect of $\mathrm{Ru}$ content on the Ti-Al phase diagram is schematically shown in Fig. 6. Ru exhibits a strong $\beta$ stabilizing effect; an excessive $\mathrm{Ru}$ content may cause the appearance of $\left(\gamma+\tau_{1}+B 2\right)$ and $\left(\alpha+\gamma+\tau_{1}+B 2\right)$ phase regions at the temperature lower than $1,250{ }^{\circ} \mathrm{C}$. Also, $\mathrm{Ru}$ plays a role in shrinking the $\alpha$ phase region, as shown in Figs. 6(b) and (c). According to the schematic diagram, the solidification path of the alloy with $0.1 \mathrm{at} \% \mathrm{Ru}$ is as follows: $\mathrm{L} \rightarrow \mathrm{L}+\beta \rightarrow \alpha \rightarrow \alpha+\gamma \rightarrow \alpha+\gamma+\mathrm{B} 2 \rightarrow \operatorname{lamellar}\left(\alpha_{2}+\gamma\right)+\gamma+\mathrm{B} 2$.
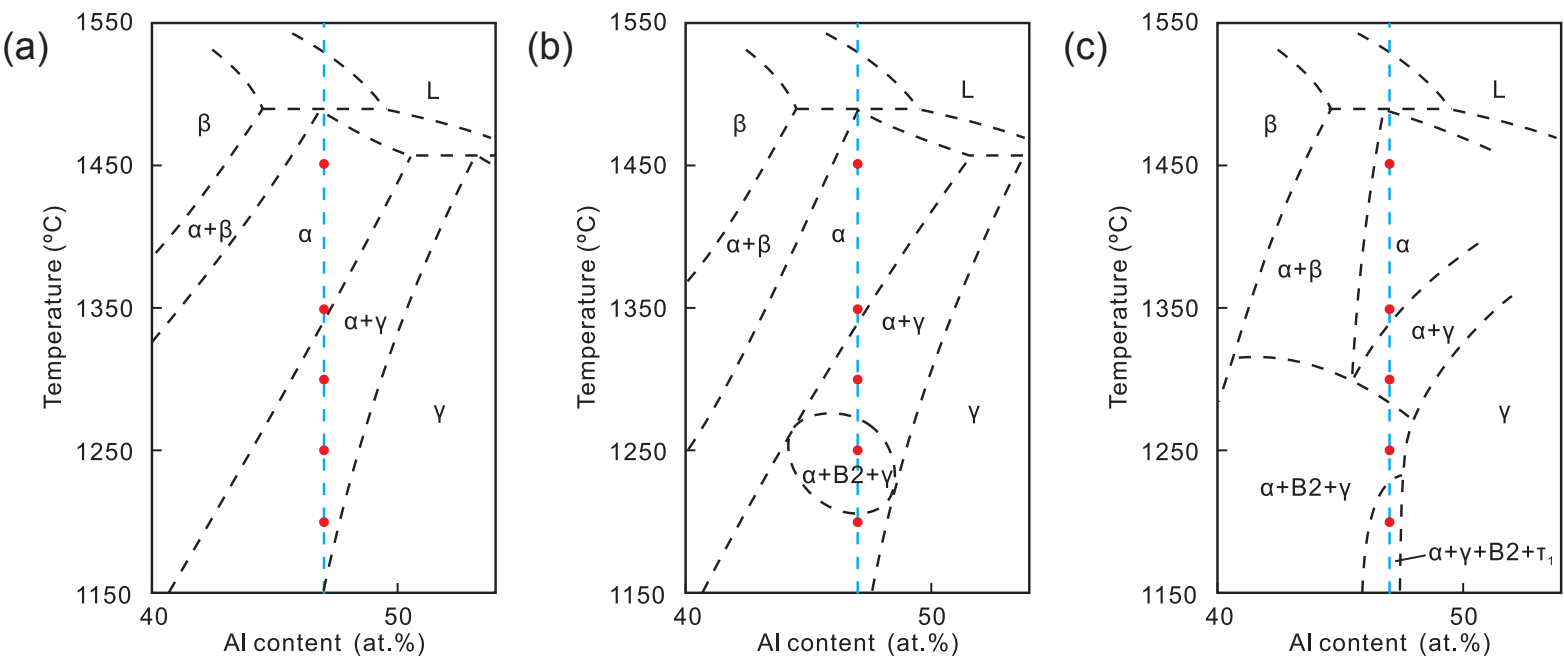

Fig. 6: Brief sketch maps showing effect of Ru content on Ti-Al phase diagram: (a) Ru=0.1at. \%, (b) Ru=0.5at.\% and (c) Ru=1.0at.\%

During solidification, $\mathrm{Ru}$ element has no influence on the peritectic reaction of $\mathrm{L}+\beta \rightarrow \alpha$, but tends to concentrate in residual liquid, and the solidification path of the interdendritic region moves toward the high-Ru content. As a consequence, the interdendritic region could sink into the $\alpha+\gamma+B 2$ three phase region, as shown in Fig. 6(b), giving a rise to the precipitation of B2 phase mixing with S-segregation. When the $\mathrm{Ru}$ content is 0.5 at.\% and 1.0 at. $\%$, the solidification path is: $\mathrm{L} \rightarrow \mathrm{L}+\beta \rightarrow \alpha \rightarrow \alpha+\gamma \rightarrow \alpha+\gamma+\mathrm{B} 2 \rightarrow \alpha+\gamma+\mathrm{B} 2+\tau_{1} \rightarrow$ lamellar $\left(\alpha_{2}+\gamma\right)+\gamma+\mathrm{B} 2+\tau_{1}$.

With the increase of Ru content, the interdendritic Ru-rich region would result in the formation of $\alpha+\gamma+B 2+\tau_{1}$ region, as shown in Fig. $6(\mathrm{c})$, and the $\tau_{1}$-containing mixture forms. The volume fraction of $\tau_{1}$-containing mixture increases with the Ru content.

The precipitation mechanism of the $\tau_{1}$-containing mixture is schematically exhibited in Fig. 7. Above $1,450{ }^{\circ} \mathrm{C}$, there is a single $\alpha$ phase field [Fig. 7(a)], suggesting that the Ru element can be completely dissolved. Upon cooling, $\gamma$ lath precipitates and $\alpha / \gamma$ colonies gradually form [Fig. 7(b)], while the $\alpha \rightarrow \gamma$ transformation would be suppressed by the partial enrichment of Ru element in blocky $\alpha$ phase. During the subsequent cooling, B2 phase precipitates directly from blocky $\alpha$ phase
[Fig. 7(c)-(d)]. Then B2 phase is penetrated by coarsened $\gamma$ lamellar ${ }^{[24]}$. In the process of discontinuous coarsening, $\gamma$ phase absorbs $\mathrm{Al}$ and excludes $\mathrm{Ru}$ atom, contributing to the precipitation of $\tau_{1}$ phase in the interface of B $2 / \gamma$ phase [Fig. 7(e)-(h)]. The discontinuous coarsened $\gamma$ phase and the blocky $\tau_{1}$ phase form alternately in a manner similar to eutectoid decomposition within B2 phase. Above all, the precipitation path of $\tau_{1}$-containing mixture is expressed as follows: $\alpha \rightarrow \alpha+\gamma \rightarrow \alpha+\gamma+$ B $2 \rightarrow \alpha+\gamma+$ B $2+\tau_{1} \rightarrow$ lamellar $\left(\alpha_{2}+\gamma\right)+\gamma+$ B $2+\tau_{1}$.

\subsection{High-temperature compression}

\subsubsection{HIP microstructure before compression}

The SEM-BSE and XRD images of HIP samples before compression are shown in Fig. 8. The HIP alloys with 0.1at.\% and 0.5 at. $\%$ Ru exhibit a duplex structure with massive $\gamma$ grains scattered at the irregular-shaped lamellar colony boundaries, as shown in Figs. 8(a) and (b). Meanwhile, the gray granular B2 phase also exists at the colony boundaries. The small amounts of B2 phase contribute to the weak diffraction peaks in Fig. 8(d).

In contrast, the microstructure of HIP alloy with 1.0at.\% $\mathrm{Ru}$ clearly changes comparing to alloys with 0.1 at.\% and 
(a)

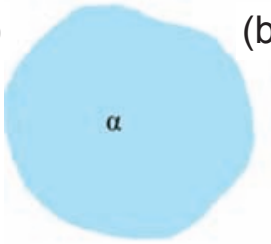

(e)

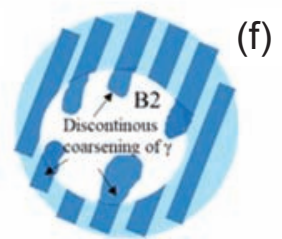

(b)
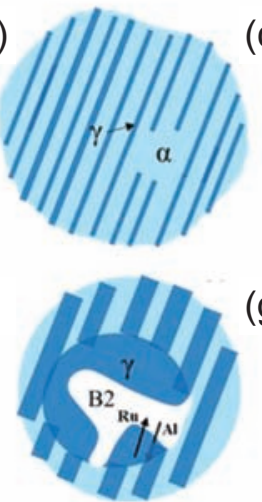

(c)

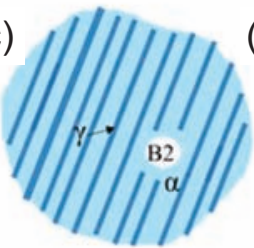

(d)

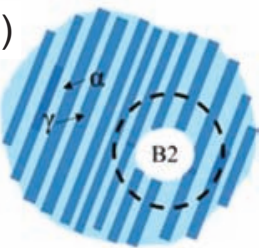

(g)

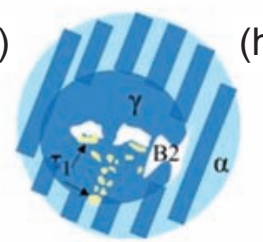

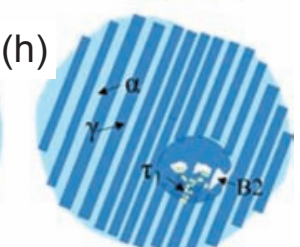

Fig. 7: Schematic diagram of precipitation mechanism of $\tau_{1}$-containing mixture

(a)

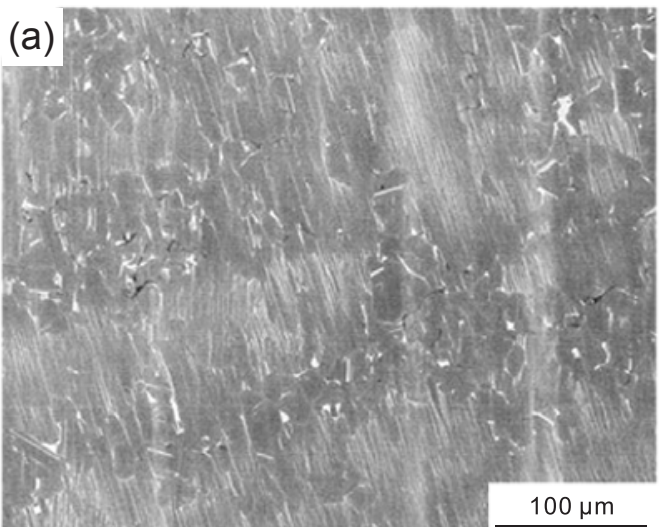

(c)

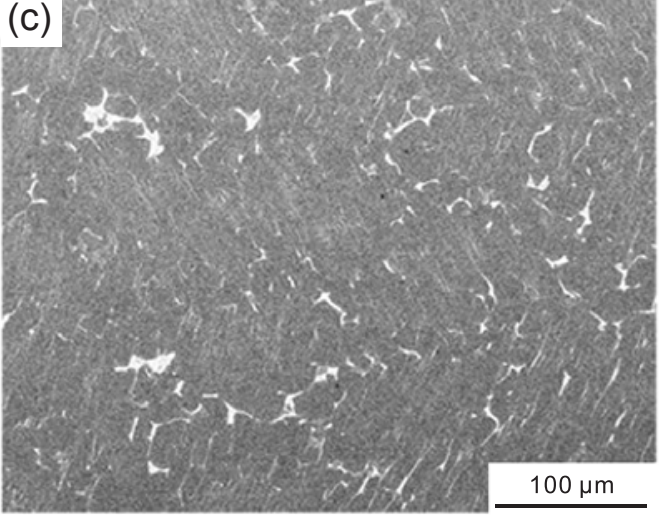

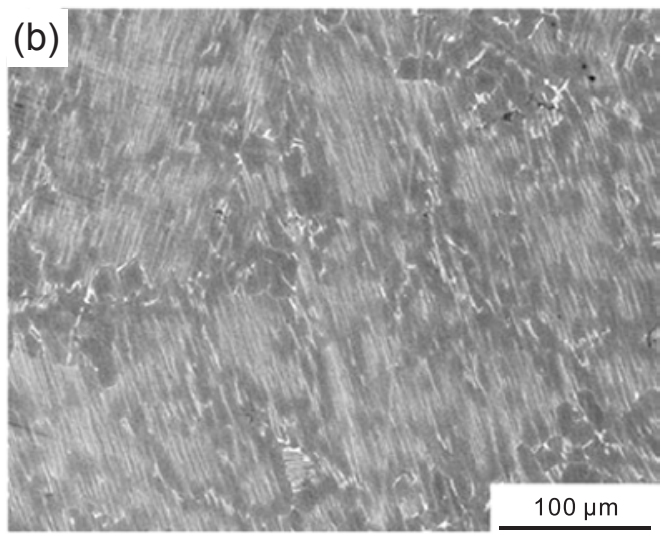

(d)

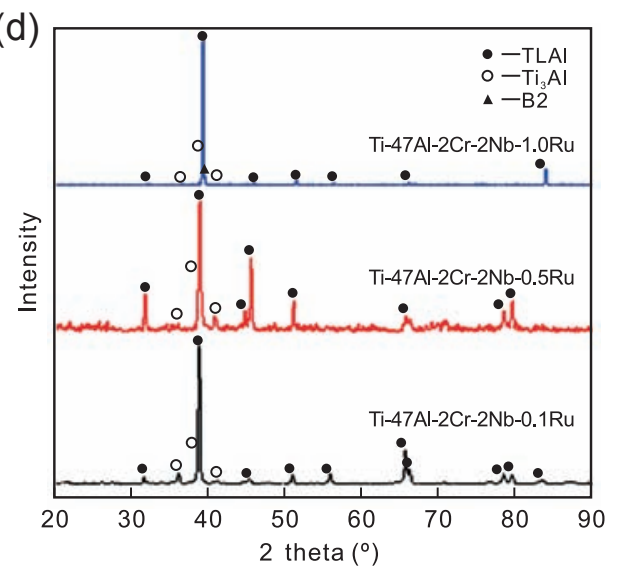

Fig. 8: Back-scattered images of HIP Ti-47AI-2Cr-2Nb-xRu alloys: (a) $x=0.1$; (b) $x=0.5$; (c) $x=1.0$; and (d) XRD patterns

0.5 at. $\%$ Ru. It is evident that the solidification segregation is hardly eliminated after the HIP process, as the $\alpha_{2} / \gamma$ lamellar structure is severely degraded, and the inhomogeneity of the chemical composition caused by solidification segregation directly promotes the formation of numerous blocky B2 and massive $\gamma$ grains, which can be confirmed by the XRD patterns in Fig. 8(d). The relative intensity of the diffraction peak of $\gamma$ phase considerably increases comparing with $\alpha_{2}$ phase. The average phase volume fractions of B2 and $\gamma$ phases in the HIP alloys with different $\mathrm{Ru}$ additions are listed in Table 3. The average volume fraction of B2 phase reaches up to $1.5 \%$ with 1.0at.\% Ru addition. Because the HIP process at $1,280{ }^{\circ} \mathrm{C}$ for $4 \mathrm{~h}$ is equivalent to an isothermal heat treatment in the middle of the $\alpha+\gamma$ phase region in the Ti-Al phase diagram ${ }^{[12]}, \mathrm{Ru}$ is
Table 3: Average volume fractions of $\mathrm{B} 2$ and $y$ phases in HIP sample

Volume fraction (\%) $\quad 0.1$ at. $\%$ Ru $\quad 0.5$ at. $\%$ Ru $\quad 1.0$ at. $\%$ Ru

$\begin{array}{cccc}\text { Y Phase } & 93.7 & 94.1 & 97.3 \\ \text { B2 phase } & 0 & 0.4 & 1.5\end{array}$

considered to shift the boundary of a two-phase region to the Al-lean side, resulting in an increased $\gamma$ phase fraction ${ }^{[25]}$.

\subsubsection{Compression test at $800{ }^{\circ} \mathrm{C}$}

Images of the samples before and after high temperature compression are presented in Fig. 9. The true stress-strain 


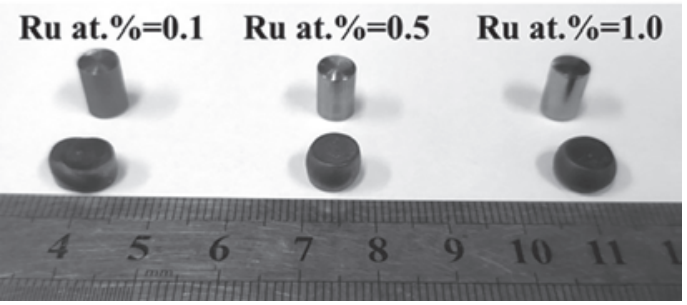

Fig. 9: Image of HIP samples before and after high temperature compression

curves obtained from high temperature compression of Ti$47 \mathrm{Al}-2 \mathrm{Cr}-2 \mathrm{Nb}-x \mathrm{Ru}(x=0.1,0.5,1.0$, at.\%) alloys are shown in Fig. 10(a). The true stress-strain curve of the alloy with $0.1 \mathrm{at} . \%$ $\mathrm{Ru}$ deformed at $800{ }^{\circ} \mathrm{C}$ displays the continuous fluctuation when the strain exceeds 0.25 , which might be caused by the occurrence of crack and its propagation in compression. The true stress-strain curves of the alloys with 0.5 at.\% and 1.0at.\% $\mathrm{Ru}$ demonstrate an obvious strain-softening behavior, which is related to the dynamic recovery process ${ }^{[26]}$.

The relationship between compressive yield strength, peak strength and $\mathrm{Ru}$ addition is plotted in Fig. 10(b). The

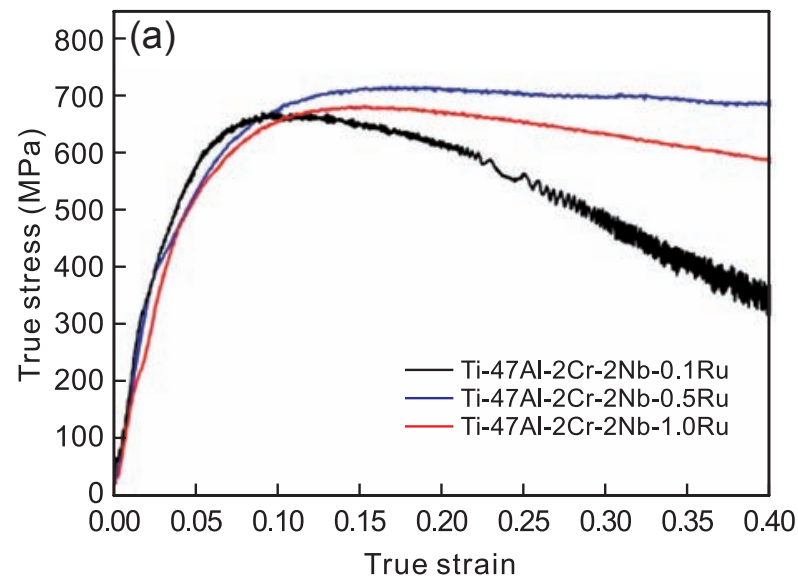

compressive yield strength of the alloy with 1.0at.\% $\mathrm{Ru}$ is $427 \mathrm{MPa}$ at $800{ }^{\circ} \mathrm{C}$, an increase of $92 \mathrm{MPa}$ compared to the alloy with 0.1 at. $\%$ Ru. While the alloy with 0.5 at.\% Ru shows the maximum compressive peak strength of $715 \mathrm{MPa}$. The decrease of compressive peak strength in the alloy with 1.0at.\% $\mathrm{Ru}$ could be a result of the deterioration of lamellar structure in Fig. 8(c). Specifically, the massive B2 phase deteriorates the crack and creep resistance of the alloy ${ }^{[27,28]}$, as the cavities and microcracks tend to nucleate and grow at the interface of $\mathrm{B} 2 / \gamma$ phase ${ }^{[29,30]}$. The increase of yield strength is mainly due to the solution strengthening effect of $\mathrm{Ru}$ element. As Ru has a smaller atomic radius $(134 \mathrm{pm})$ than $\mathrm{Ti}(147 \mathrm{pm})$ and $\mathrm{Al}$ (143 pm), the unit cell volume of $\gamma$ phase keeps decreasing up to 2 at.\% of $\mathrm{Ru}$ addition, while the degree of unit cell volume shrinkage is weakened at higher content of Ru addition more than 0.5 at. $\%{ }^{[9]}$. Besides, Kim et al. suggested the addition of $0.5 \mathrm{at} . \% \mathrm{Ru}$ could obtain the minimum axial ratio for the solubility limit of $\mathrm{Ru}$ in $\gamma$ phase ${ }^{[9]}$. Therefore, considering the effect of $\mathrm{Ru}$ element on the microstructure and compression property of Ti-47Al-2Cr-2Nb alloy, the content of Ru addition should be controlled within 0.5 at. $\%$.

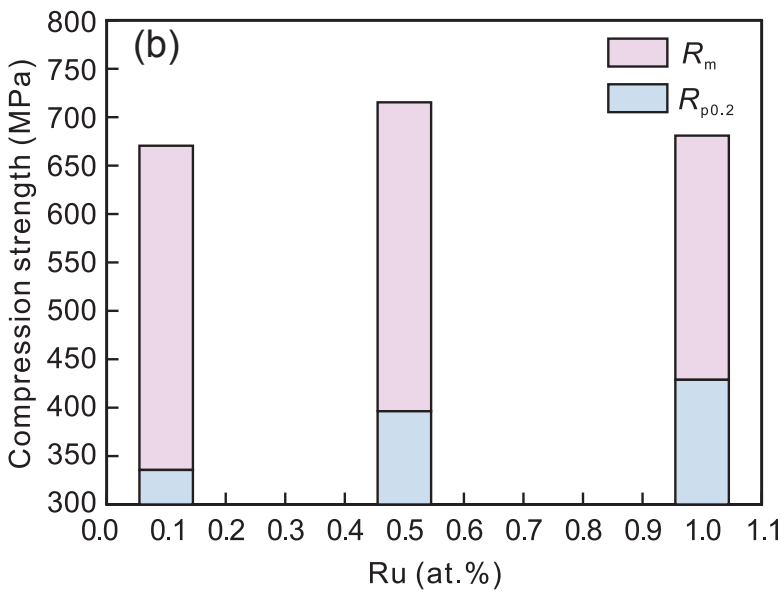

Fig. 10: (a) Compressive stress-strain curves of Ti-47Al-2Cr-2Nb-xRu alloys $(x=0.1 .0 .5,1.0)$ tested with a strain rate of $1 \times 10^{-3} \mathrm{~s}^{-1}$ at $800^{\circ} \mathrm{C}$; (b) High temperature compression yield strength $\left(R_{\mathrm{p} 0.2}\right)$ and compression peak strength $\left(R_{\mathrm{m}}\right)$ of Ti-47Al-2Cr-2Nb alloys with different Ru contents

\section{Conclusions}

(1) Ru element tends to distribute in the interdendritic region during solidification, which promotes the formation of $\tau_{1}$-containing mixture. The addition of Ru element could apparently refine the as-cast microstructure.

(2) The precipitation mechanism of $\tau_{1}$-containing mixture in Ti-47Al-2Cr-2Nb- $x \mathrm{Ru}(x=0.1,0.5,1.0$, at.\%) alloys attributes to the Ru segregation. The discontinuous coarsened $\gamma$ phase and block $\tau_{1}$ phase forms alternately in a manner of similar to eutectoid decomposition within $\mathrm{B} 2$ phase.

(3) The compression yield strength of Ti-47Al-2Cr- $2 \mathrm{Nb}$ alloy increases up to $427 \mathrm{MPa}$ at $800{ }^{\circ} \mathrm{C}$ with a $1.0 \mathrm{at} . \% \mathrm{Ru}$ addition, which is mainly due to the solution strengthening effect of Ru.

\section{Acknowledgments}

The authors gratefully acknowledge the financial support from the National Natural Science Foundation of China (No. 51774238), the Open Project of Key Laboratory for Magnetism and Magnetic Materials of the Ministry of Education (No. LZUMMM2020008), the Natural Science Fundamental Research Foundation of Shaanxi Province (No. 2020JM-086) and the 2018 Joint Foundation of Ministry of Education for Equipment Pre-research (No. 6141A020332).

\section{References}

[1] Clemens H, Smarsly W. Light-weight intermetallic titanium aluminides - Status of research and development. Advanced Materials Research, 2011, 278: 551-556. 
[2] Jiang Z H, Zhao C Z, Yu J J, et al. Effect of Cr on microstructure and oxidation behavior of TiAl-based alloy with high $\mathrm{Nb}$. China Foundry, 2018, 15(1): 17-22.

[3] Liu X W, Liu F C, Du H, et al. Effect of hydrogen on interfacial reaction between TiAl alloy melt and graphite mold. Intermetallics, 2014, 53: 107-111.

[4] Appel F, Clemens H, Fischer F D. Modeling concepts for intermetallic titanium aluminides. Progress in Materials Science, 2016, 81: 55-124.

[5] Dong C L, Yu H C, Jiao Z H, et al. Low cycle fatigue, creep and creep-fatigue interaction behavior of a TiAl alloy at high temperatures. Scripta Materialia, 2018, 144: 60-63.

[6] Kim Y W, Kim S L. Advances in gammalloy materials-processesapplication technology: successes, dilemmas, and future. JOM, 2018, 70(4): 553-560.

[7] Dong C L, Jiao Z H, Yu H C, et al. Effect of dwell condition on fatigue behavior of a high-Nb TiAl alloy at $750^{\circ} \mathrm{C}$. Intermetallics, 2017, 91: 1-7.

[8] Khataee A, Flower H M, West D R F. New titanium-aluminum-X alloys for aerospace applications. Journal of Materials Engineering, 1988, 10(1): 37-44.

[9] Kim S, Nguyen-Manh D, Smith G D W, et al. Site preference of $\mathrm{Ru}$ and $\mathrm{Pd}$ additions to $\mathrm{y}$-based TiAl intermetallics. Philosophical Magazine A, 2000, 80(11): 2489-2508.

[10] Grytsiv A, Rogl P, Schmidt $\mathrm{H}$, et al. Constitution of the ternary system Al-Ru-Ti (Aluminum-Ruthenium-Titanium). Journal of Phase Equilibria, 2003, 24(6): 511-527.

[11] Liu Q, Nash P. The effect of ruthenium addition on the microstructure and mechanical properties of TiAl alloys. Intermetallics, 2011, 19(9): 1282-1290.

[12] Schuster J C, Palm M. Reassessment of the binary aluminumtitanium phase diagram. Journal of Phase Equilibria and Diffusion, 2006, 27(3): 255-277.

[13] Wu Y L, Hu R, Yang J R, et al. Phase transformation and fine fully lamellar (FFL) structure formation in a high Nb-containing beta-gamma TiAl Alloy. Advanced Engineering Materials, 2019, 21(8): 1900244.

[14] Ding X F, Zhang L W, He J P, et al. As-cast microstructure characteristics dependent on solidification mode in TiAl-Nb alloys. Journal of Alloys and Compounds, 2019, 809: 1-9.

[15] Chen G L, Xu X J, Teng Z K, et al. Microsegregation in high $\mathrm{Nb}$ containing $\mathrm{TiAl}$ alloy ingots beyond laboratory scale. Intermetallics, 2007, 15(5): 625-631.

[16] Daloz D, Hecht U, Zollinger J, et al. Microsegregation, macrosegregation and related phase transformations in TiAl alloys. Intermetallics, 2011, 19(6): 749-756.

[17] Mwamba L, Cornish L A, Lingen E V D. Microstructural, mechanical, and oxidation property evolution of gamma-TiAl alloy with addition of precious metals. Journal of the Southern African Institute of Mining and Metallurgy, 2012, 112: 517-526.
[18] Luo L S, Liu T, Li K, et al. Microstructures, micro-segregation and solidification path of directionally solidified Ti-45Al-5Nb alloy. China Foundry, 2016, 13(2): 107-113.

[19] Zhu D D, Wang H W, Qi J Q, et al. Effect of Cr addition on microstructures and nanohardness of rapidly solidified Ti-48AI alloy. Materials Science and Technology, 2012, 28(12): 13851390.

[20] Wu Y L, Hu R, Yang J R. On the eutectoid decomposition of $\alpha \rightarrow Y+T_{1}$ in a Ru-containing TiAl alloy. Journal of Alloys and Compounds, 2019, 790: 42-47.

[21] Contieri R J, Lopes E S N, Caram R, et al. Effects of cooling rate on the microstructure and solute partitioning in near eutectoid Ti-Cu alloys. Philosophical Magazine, 2014, 94(21): 2350-2371.

[22] Zhang X M, Deng H Q, Xiao S F, et al. Diffusion of Co, Ru and $\mathrm{Re}$ in Ni-based superalloys: A first-principles study. Journal of Alloys and Compounds, 2014, 588: 163-169.

[23] Cheng T T, Loretto $M H$. The decomposition of the beta phase in Ti-44AI-8Nb and Ti-44Al-4Nb-4Zr-0.2Si alloys. Acta Materialia, 1998, 46(13): 4801-4819.

[24] Cao B, Yang J R, Wang $X$ Y, et al. Microstructure evolution and mechanical properties of a Ti-45Al-8.5Nb-(W, B, Y) alloy obtained by controlled cooling from a single $\beta$ region. Journal of Alloys and Compounds, 2018, 740: 1140-1148.

[25] Kim S, Larson D J, Smith G D W. Alloying elements partitioning in TiAl-Ru intermetallic alloys. Intermetallics, 1999, 7(11): 12831290.

[26] Kim J H, Chang Y W, Lee C S, et al. High-temperature deformation behavior of a gamma TiAl alloy - microstructural evolution and mechanisms. Metallurgical and Materials Transactions A, 2003, 34(10): 2165-2176.

[27] Nishikiori S, Takahashi S, Satou S, et al. Microstructure and creep strength of fully-lamellar TiAl alloys containing betaphase. Materials Science and Engineering: A, 2002, 329-331: 802-809.

[28] Zhu B, Xue X Y, Kou H C, et al. Effect of microstructure on the fracture toughness of multi-phase high $\mathrm{Nb}$-containing TiAl alloys. Intermetallics, 2018, 100: 142-150.

[29] Wang $Q$, Chen R R, Yang $Y H$, et al. Effects of $V$ and $B, Y$ additions on the microstructure and creep behaviour of high$\mathrm{Nb}$ TiAl alloys. Journal of Alloys and Compounds, 2018, 747: 640-647.

[30] Wang Q, Chen R R, Yang Y H, et al. Improvement of the creep lifetimes and microstructural stability of $\beta$-solidifying $Y$-TiAl by cold crucible directional solidification. Intermetallics, 2018, 100: 104-111. 